\title{
Precancer and cancer in extensive ulcerative colitis: findings among 401 patients over 22 years
}

\author{
J E Lennard-Jones, D M Melville, B C Morson, J K Ritchie, C B Williams
}

\begin{abstract}
Patients with extensive ulcerative colitis who do not need early surgery have been offered regular examination with the aim of detecting precancerous change (dysplasia) or early colorectal carcinoma. Outpatient visits with clinical examination, sigmoidoscopy, and biopsy were supplemented by two-yearly colonoscopy after the disease course reached 10 years. During the 22 year period from the beginning of 1966 to the end of 1987, 401 patients entered the programme and together contributed 4048 patient-years of observation. Apart from nine patients who left the country, follow up is complete until 1986 or 1987. Colorectal carcinoma developed in 22 patients and, in a further 12, biopsy evidence of precancer, described as severe/high grade dysplasia, was confirmed in a colectomy specimen. The cumulative probability of developing carcinoma was $3 \%$ at 15 years, 5\% at 20 years, and $9 \%$ at 25 years; corresponding figures for precancer or carcinoma, or both were $4 \%, 7 \%$, and $13 \%$. Five patients died of colorectal carcinoma, two while under regular observation and three after developing carcinoma four to six years after their last attendance. Among the 17 patients who developed carcinoma while under observation, the Dukes stage was A or B in 12. Patients with extensive colitis whose disability does not warrant early surgery have a clinically important cancer risk after the disease has been present for 10 years. Our results suggest that follow up in the manner described reduces the mortality from this complication. Further work is needed to define the optimum method of surveillance and show if it is cost effective.
\end{abstract}

Many studies have shown that there is an increased risk of colorectal carcinoma in ulcerative colitis and that the risk is greatest among patients in whom most or all of the colon is affected. Many of these patients are treated surgically and it is important to define the cancer risk among the remainder whose symptoms do not warrant colectomy because of disability from their disease. To this end, a follow up programme was begun in 1966 among patients with colitis attending a medical clinic and for whom surgical treatment did not seem indicated at the time of inclusion. The detection of possible precancerous dysplastic changes in rectal mucosal biopsy specimens was described from this hospital at the same time,' and a second aim of this study was to assess the usefulness of regular endoscopy and biopsy for the detection of dysplastic changes or early carcinoma. Results from this study up to the introduction of colonoscopy were presented in $1974,{ }^{2}$ and with colonoscopy in 1977 and $1983 .{ }^{3+}$ This analysis after 22 years reassesses the cancer risk in this prospective series and examines factors contributing to the outcome.

\section{Method}

\section{PATIENT SELECTION}

All patients with extensive ulcerative colitis diagnosed by sigmoidoscopic, histological, and radiological criteria seen in the medical clinic were entered into this study provided that they wished to continue under the care of this hospital and that early surgery was not advisable. Extensive colitis was defined by radiological changes extending up to and including the hepatic flexure. Patients came from three sources: 65 patients seen at St Mark's hospital before 1 January 1966 and known to have extensive disease; 242 referred later with established extensive disease; and 94 patients with distal disease when first seen at St Mark's but subsequent progression to radiologically extensive disease as defined above. These patients were referred to a specialist hospital and it is not possible to define the population from which they came.

An additional 62 patients with disease shown to affect the right colon on colonoscopic biopsy specimen but not on air contrast barium enema have been excluded from this analysis as we wished all patients to conform to the original criteria. These patients, however, were followed in exactly the same way as those with radiological extensive disease and results will be reported when adequate data are available.

\section{CONDUCT OF STUDY}

In all patients the presence of carcinoma was ruled out as far as possible by the original barium enema before entry, and all patients were followed systematically from that time unless they defaulted. During the period 1966-1974, clinical assessment, sigmoidoscopy, and rectal biopsy were undertaken every six months. After an initial assessment of colonoscopy between 1971 and 1974, this examination was arranged every two years once the duration of disease reached 10 years. At the same time the frequency of clinic visits was reduced to once a year or sometimes the alternate year between colonoscopies provided that patients were well and no dysplasia was detected. More frequent appointments were made for patients who needed treatment of their colitis or close supervision because dysplasia was found. Barium enema was used only when colonoscopy was incomplete or 
TABLE I The status of the patients at the time of analysis

\begin{tabular}{lccc}
\hline & $\begin{array}{l}\text { During } \\
\text { surveillance }\end{array}$ & $\begin{array}{l}\text { After leaving } \\
\text { surveillance }\end{array}$ & Total \\
\hline Operation & 90 & 9 & 99 \\
Death (without operation) & 27 & 4 & 31 \\
Alive (without operation) & 227 & 35 & 262 \\
Emigrated & - & 9 & 9 \\
& 344 & 57 & 401 \\
\hline
\end{tabular}

refused. If a patient failed to attend for a clinic visit or colonoscopy, one or more letters were sent encouraging re-attendance.

\section{ENDOSCOPY}

A rigid $25 \mathrm{~cm}$ sigmoidoscope was used in the outpatient clinic without prior bowel preparation and a single biopsy specimen was taken. Colonoscopy was performed after full bowel preparation with the aim of examining the whole large intestine, and biopsy specimens were taken at approximately $10 \mathrm{~cm}$ intervals throughout the colon and rectum.

\section{PATHOLOGICAL ASSESSMENT}

Initially dysplasia was described as 'suspicious of' or showing 'definite' precancer; subsequently it was graded as 'mild', 'moderate', or 'severe'. Since 1983 the internationally recommended description of 'indefinite', 'low grade', and 'high grade' dysplasia has been followed. ${ }^{5}$ For this analysis 'precancer', 'severe dysplasia', and 'high grade dysplasia' are regarded as equivalent. Lesser degrees of dysplasia including mild, moderate, and low grade have been grouped together. The biopsy specimens have not been regraded for the purpose of this analysis because clinical decisions were governed by the pathological report at the time.

\section{Results}

\section{OVERALL RESULTS}

Between 1 January 1966 and 31 December 1987, 401 patients ( 230 men; 171 women) entered the follow up programme. Follow up is complete for all patients except for nine who left the country, and the status of the 401 patients, on a date between 1.1.86 and 31.12.87, is shown in Table I.

\section{PATIENT COMPLIANCE}

As a measure of compliance within the programme, the maximum interval between two consecutive visits for each patient has been recorded. The interval was less than one year for 148 patients, less than two years for 172 , less than three years for 45 , and more than three years for 36 patients.

Ten patients refused colonoscopy, five other patients accepted one colonoscopy but refused another, and seven patients refused a further colonoscopy after more than one examination.

After a variable period, 57 patients $(14 \%)$ left the programme because of emigration (9), follow up at another hospital (18), advancing age or another illness (5), or because they declined to attend (25).

\section{OUTCOME FOR PATIENTS WITHIN SURVEILLANCE PROGRAMME}

Of 344 patients followed within the surveillance programme for a total of 3706 patient years until one of the end points shown in Table I, 90 were treated surgically. Seventeen patients who underwent surgery had developed carcinoma: Dukes stage A (9); B (3); C (3); and disseminated (2) (patients 9 and 12) (Table II). In 12 patients

TABLE II Details of patients who developed carcinoma while under surveillance

\begin{tabular}{|c|c|c|c|c|c|c|c|c|c|c|}
\hline Patient & Sex & $\begin{array}{l}\text { Age } \\
(y r s)\end{array}$ & $\begin{array}{l}\text { History } \\
\text { (yrs) }\end{array}$ & Site & $\begin{array}{l}\text { Dukes } \\
\text { stage }\end{array}$ & $\begin{array}{l}\text { Histological } \\
\text { differentiation }\end{array}$ & Indications for operation & Mode of diagnosis & Outcome & \\
\hline 1 & $M$ & 47 & 24 & A & B & Moderate & Disability/dysplasia rectum & Specimen & Al $21 y$ & $0 \mathrm{~m}$ \\
\hline 2 & $\mathrm{~F}$ & 52 & 28 & $\mathbf{R}$ & A & Well & Dysplasia rectum & Specimen & Al $20 y$ & $3 \mathrm{~m}$ \\
\hline 3 & $\mathrm{~F}$ & 42 & 15 & $\mathrm{H}$ & A & Well & Disability/dysplasia rectum & Specimen & D $6 y$ & $4 \mathrm{~m}$ (unrelated) \\
\hline 4 & $\mathbf{M}$ & 43 & 13 & $\mathrm{~T}$ & A & Moderate & Dysplasia colon & Specimen & Al $12 y$ & $2 \mathrm{~m}$ \\
\hline 5 & $M$ & 55 & 24 & $\mathrm{~A} / \mathrm{T}$ & $\mathrm{A} / \mathrm{A}$ & Well & Dysplasia colon & Specimen & Al $11 y$ & $1 \mathrm{~m}$ \\
\hline 6 & $\mathrm{~F}$ & 32 & 13 & $\mathrm{~T}$ & C & Poor & Perforated carcinoma & Laparotomy & Al $10 y$ & $6 \mathrm{~m}$ \\
\hline 7 & $\mathrm{~F}$ & 65 & 11 & A & B & Moderate & Tumour on barium enema & Barium enema & Al $10 y$ & $4 \mathrm{~m}$ \\
\hline 8 & $\mathbf{F}$ & 56 & 12 & $\mathrm{~T} / \mathrm{T}$ & $\mathrm{A} / \mathrm{A}$ & Well & Disability/dysplasia rectum & Specimen & D $2 y$ & $\operatorname{lm}$ (unrelated) \\
\hline 9 & $\mathrm{~F}$ & 32 & 16 & $\mathrm{H}$ & - & Poor & Abdominal pain + mass & Laparotomy & & $\operatorname{lm}$ (carcinoma) \\
\hline 10 & $M$ & 60 & 13 & $\mathbf{R}$ & A & Moderate & Carcinoma & Sigmoidoscopy & Al $7 y$ & $8 \mathrm{~m}$ \\
\hline 11 & $\mathrm{~F}$ & 54 & 29 & $\mathbf{R}$ & A & Well & Disability/dysplasia rectum & Specimen & Al $6 y$ & $9 \mathrm{~m}$ \\
\hline 12 & $M$ & 25 & 12 & $\mathrm{~S}$ & $\mathrm{C}$ & Poor & Tumour on barium enema & Barium enema & $\mathrm{D}$ & $6 \mathrm{~m}$ (carcinoma) \\
\hline 13 & M & 73 & 42 & $\mathbf{R}$ & A & Moderate & Carcinoma & Sigmoidoscopy & Al $4 y$ & $\operatorname{lm}$ \\
\hline 14 & $\mathbf{M}$ & 41 & 20 & $\mathrm{R} / \mathrm{S}$ & $\mathrm{Cl} / \mathrm{A}$ & Moderate & Carcinoma & Sigmoidoscopy & Al ly & $2 m$ \\
\hline 15 & $\mathrm{~F}$ & 53 & 26 & $\mathbf{R}$ & $\mathrm{Cl}$ & Poor & Carcinoma & Rectal examination & $\mathrm{Al}$ & $6 \mathrm{~m}$ \\
\hline 16 & $M$ & 76 & 32 & $\mathbf{R}$ & A & Well & Carcinoma & Colonoscopy & $\mathrm{Al}$ & $\operatorname{lm}$ \\
\hline 17 & $M$ & 36 & 21 & $\mathbf{R}$ & B & Poor & Dysplasia rectum & Specimen & $\mathrm{Al}$ & $\operatorname{lm}$ \\
\hline
\end{tabular}

$\mathrm{A}=$ ascending colon $\mathrm{H}=$ hepatic flexure $\mathrm{T}=$ transverse colon; $\mathrm{S}=$ sigmoid colon $\mathrm{R}=$ rectum $\mathrm{Al}=$ alive $\mathrm{D}=$ dead.

TABLE III Details of patients who developed carcinoma after leaving the surveillance programme

\begin{tabular}{|c|c|c|c|c|c|c|c|c|c|c|}
\hline Patient & Sex & $\begin{array}{l}\text { Age } \\
\text { (yrs) }\end{array}$ & $\begin{array}{l}\text { History } \\
\text { (yrs) }\end{array}$ & Site & $\begin{array}{l}\text { Dukes } \\
\text { stage }\end{array}$ & $\begin{array}{l}\text { Histological } \\
\text { differentiation }\end{array}$ & Indications for operation & Mode of diagnosis & Outcome & \\
\hline $\begin{array}{l}18 \\
19 \\
20 \\
21 \\
22\end{array}$ & $\begin{array}{l}M \\
M \\
F \\
M \\
M\end{array}$ & $\begin{array}{l}71 \\
26 \\
49 \\
75 \\
38\end{array}$ & $\begin{array}{l}30 \\
12 \\
21 \\
17 \\
16\end{array}$ & $\begin{array}{l}\mathrm{H} / \mathrm{R} \\
\mathrm{T} \\
\mathrm{H} \\
\mathbf{R} \\
\mathbf{R}\end{array}$ & $\begin{array}{l}\mathrm{B} / \mathrm{A} \\
\mathrm{A} \\
\mathrm{C} \\
- \\
-\end{array}$ & $\begin{array}{l}\text { Well } \\
\text { Poor } \\
\text { Poor } \\
\text { Poor } \\
\text { Unknown }\end{array}$ & $\begin{array}{l}\text { Suspicious barium enema } \\
\text { Disability } \\
\text { Perforated carcinoma } \\
\text { Carcinoma } \\
\text { Carcinoma }\end{array}$ & $\begin{array}{l}\text { Laparotomy } \\
\text { Specimen } \\
\text { Laparotomy } \\
\text { Sigmoidoscopy } \\
\text { Rectal examination }\end{array}$ & $\begin{array}{ll}\mathrm{Al} & 6 \mathrm{y} \\
\mathrm{Al} & 6 \mathrm{y} \\
\mathrm{D} & \\
\mathrm{D} & \\
\mathrm{D} & \end{array}$ & $\begin{array}{l}6 \mathrm{~m} \\
0 \mathrm{~m} \\
5 \mathrm{~m} \text { (carcinoma) } \\
8 \mathrm{~m} \text { (carcinoma) } \\
6 \mathrm{~m} \text { (carcinoma) }\end{array}$ \\
\hline
\end{tabular}

$\mathbf{H}=$ hepatic flexure; $\mathrm{T}=$ transverse colon; $\mathbf{R}=$ rectum; $\mathrm{Al}=$ alive $\mathrm{D}=$ dead 
operated on for severe/high grade dysplasia, these changes without carcinoma were found in the specimen. The remaining 61 patients underwent colectomy for acute or chronic symptoms.

\section{OUTCOME FOR PATIENTS WHO LEFT THE SURVEILLANCE PROGRAMME}

Of 48 patients (excluding those who emigrated) who left the surveillance programme and were followed for 342 patient years, five were treated surgically because they had developed a carcinoma at intervals of four to six years from their last clinic visit. Three died from disseminated carcinoma and the other two had Dukes A or B lesions (Table III).

\section{RISK OF CARCINOMA IN EXTENSIVE \\ COLITIS}

Including all the follow up data, the cumulative risk of developing carcinoma (with $95 \%$ confidence limits) using the method of life table analysis described by Kaplan and Meier," was $3 \%(0-13 \%)$ at 15 years, $5 \%(0-18 \%)$ at 20 years, and $9 \%(0-32 \%)$ at 25 years. The cumulative risk of developing carcinoma or severe dysplasia (confirmed in the surgical specimen) was $4 \%(0$ $13 \%)$ at 15 years, $7 \%(0-21 \%)$ at 20 years, and $13 \%(0-38 \%)$ at 25 years.

The risk of carcinoma can also be expressed in terms of carcinomas developing per year of patient follow up at varying times from the onset of colitis as shown in Table IV. The risk of carcinoma developing after the onset of colitis was $1 / 137$ years for the second decade and $1 / 103$ years for the third decade. If the patients who had high grade/severe dysplasia (in the surgical specimen) are included with those who developed carcinoma, these figures rise to $1 / 89$ years of patient follow up for the second decade and 1/71 years of patient follow up for the third decade. No carcinoma was diagnosed less than 10 years from the onset of colitis.

SITE AND MODE OF DIAGNOSIS OF CARCINOMA AND DYSPLASIA

Those cancers discovered because of the detec-

TABLE IV Risk of carcinoma for years of patient follow up

\begin{tabular}{|c|c|c|c|c|c|c|}
\hline \multirow{2}{*}{$\begin{array}{l}\text { Duration } \\
\text { of } \\
\text { symptoms }\end{array}$} & \multirow[b]{2}{*}{$\begin{array}{l}\text { No of } \\
\text { patients }\end{array}$} & \multirow[b]{2}{*}{$\begin{array}{l}\text { Patient yrs } \\
\text { of duration }\end{array}$} & \multicolumn{2}{|c|}{ No of patients with } & \multicolumn{2}{|c|}{ Risk per patient yr } \\
\hline & & & Carcinoma & $\begin{array}{l}\text { Severe/high grade } \\
\text { dysplasia }\end{array}$ & Carcinoma & $\begin{array}{l}\text { Severe/high grade } \\
\text { dysplasia or carcinoma }\end{array}$ \\
\hline$<10$ & 269 & 1406 & 0 & 1 & 0 & 1 in 1406 \\
\hline $10-20$ & 252 & 1512 & 11 & 6 & 1 in 137 & 1 in 89 \\
\hline$>20$ & 187 & 1130 & 11 & 5 & 1 in 103 & 1 in 71 \\
\hline
\end{tabular}

TABLE V Dukes stage correlated with reason for operation in 22 patients with carcinoma

\begin{tabular}{|c|c|c|c|c|}
\hline \multirow[b]{2}{*}{ Reason for operation } & \multicolumn{3}{|c|}{ Dukes stage } & \multirow{2}{*}{$\begin{array}{l}\text { Disseminated at } \\
\text { time of operation }\end{array}$} \\
\hline & $A$ & $B$ & $C$ & \\
\hline Dysplasia \pm disability & 6 & 2 & & \\
\hline Disability (cancer unsuspected) & 1 & & & \\
\hline \multicolumn{5}{|l|}{ Cancer detected: } \\
\hline Sigmoidoscopy & 2 & & 1 & 1 \\
\hline Colonoscopy & 1 & & & \\
\hline Barium enema & & 1 & 1 & \\
\hline Palpable on digital examination & & & $\mathrm{i}$ & 1 \\
\hline Urgent laparotomy & & 1 & $\mathrm{i}$ & 2 \\
\hline
\end{tabular}

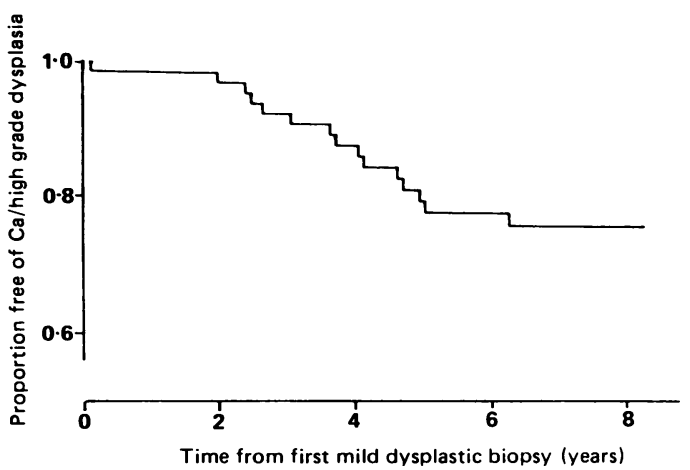

Figure: Proportion of patients free of carcinoma $(\mathrm{Ca})$ or high grade dysplasia against time (in yrs) from the first biopsy specimen showing dysplasia of low, mild, or moderate grade. Each step represents one or more patients developing carcinoma or high grade dysplasia.

tion of dysplasia were predominantly Dukes A, those detected by barium enema were Dukes B or $\mathrm{C}$, and those detected at laparotomy were predominantly disseminated and inoperable (Table V). Thirteen of the 26 tumours in 22 patients were situated in the rectum (11) or sigmoid colon (2). The remainder were fairly evenly distributed around the transverse and ascending colon.

Among the 17 patients who developed a carcinoma while attending follow up, one lesion (patient 15) was detected as a nodule on digital examination of the rectum, three distal macroscopic tumours (patients 10,11, and 14) were found at sigmoidoscopy and one at colonoscopy (patient 16). Two tumours detected at barium enema were in one patient who refused colonoscopy and another in whom it was incomplete. In eight patients, six with severe/high grade and two with moderate/low grade dysplasia, a carcinoma was an unexpected finding in the excised colon. Two tumours were diagnosed clinically, one presented as an abdominal mass and the other by perforation.

\section{ENDOSCOPY}

(a) Sigmoidoscopy. Sigmoidoscopy with biopsy was performed on 3170 occasions. Three macroscopic carcinomas were detected (Dukes stage A, $A$, and $C$ ) during surveillance examinations as an ulcer with raised edges (1) or as a broad-based polyp (2). Sixteen biopsy specimens showing high grade dysplasia were obtained on sigmoidoscopy from the rectum or distal sigmoid colon.

(b) Colonoscopy. Colonoscopy was performed in 245 patients on 811 occasions. The patients who did not have a colonoscopy were those with a total history of symptoms under 10 years and the 10 patients who refused examination. The caecum was reached during all but 42 examinations, and in 15 of these the instrument reached at least the hepatic flexure. There was no complication from colonoscopy.

The first three colonoscopies were performed in 1971, and 24 examinations were undertaken during the next three years. The decision was made in 1974 to include regular colonoscopy once the disease duration reached 10 years and 42 examinations were performed in 1975 . Thereafter the average annual numbers of examina- 
TABLE VI Correlation between the number of colonoscopies performed in different patients, the median interval between examinations, and the findings on endoscopic biopsy specimen

\begin{tabular}{|c|c|c|c|c|c|c|c|c|c|}
\hline & \multicolumn{8}{|c|}{ No of colonoscopies } & \multirow[b]{2}{*}{ Total } \\
\hline & 1 & 2 & 3 & 4 & 5 & 6 & 7 & 8 & \\
\hline No of patients & 68 & 41 & 28 & 31 & 32 & 26 & 15 & 4 & 245 \\
\hline No of colonoscopies & 68 & 82 & 84 & 124 & 160 & 156 & 105 & 32 & 811 \\
\hline Median interval (yrs) & - & 2 & 2 & 2 & $2 \cdot 2$ & $2 \cdot 2$ & 1.9 & 1.9 & - \\
\hline No dysplasia/carcinoma & 59 & 74 & 77 & 118 & 149 & 139 & 92 & 28 & 730 \\
\hline Low grade dysplasia & 6 & 7 & 5 & 6 & 11 & 14 & 13 & 3 & 65 \\
\hline High grade dysplasia & 1 & 1 & 2 & 2 & - & 3 & 1 & 1 & 11 \\
\hline Unclassified dysplasia & 1 & 1 & $=$ & - & - & 1 & - & - & 3 \\
\hline Carcinoma & 1 & - & - & $1^{\star}$ & - & - & - & - & 2 \\
\hline
\end{tabular}

$\star$ Dysplastic mass proved to be a carcinoma

tions during successive three year periods until 1987 were $41,55,69$, and 82 respectively.

The findings at the initial colonoscopy in the 245 patients were: no dysplasia or carcinoma (202); mild/low grade dysplasia (38); severe/high grade dysplasia (2); unclassified dysplasia (2); and carcinoma (1). Among the 38 patients with low grade dysplasia, biopsy specimens in five subsequently showed high grade dysplasia over a period of one to eight years; all were treated surgically and changes of high grade dysplasia were found in the colectomy specimen in every case. In three patients a carcinoma (Dukes A, C, and disseminated) was diagnosed later after one, two, and 11 years respectively. The remaining 30 patients with low grade dysplasia did not develop high grade dysplasia or carcinoma over a median follow up of 11 years (range 0-14 years). Both patients with high grade dysplasia at the first colonoscopy were found to have a carcinoma within two years (Dukes $\mathrm{A}$ in each case). The single patient with carcinoma had previously refused colonoscopy; a tumour was shown on barium enema after which colonoscopy was accepted.

In the 245 patients colonoscopy was performed only once in 68 , and between two and eight times in the remaining 177 . Table VI shows that the median interval between successive examinations approximated to the two years planned. Mild/low grade dysplasia was reported in biopsy specimens from 65 of the colonoscopies, 38 at the first and 27 at subsequent examinations. The finding tended to be inconstant. High grade dysplasia was found on 11 occasions, twice at the first and nine times during the subsequent 566 examinations. One carcinoma was detected by colonoscopy (Dukes A) (excluding the patient diagnosed on barium enema) in a patient with a dysplastic mass, high grade on biopsy specimen, which proved to be a carcinoma.

\section{DYSPLASIA}

Out of 24 patients who had a biopsy specimen showing high grade dysplasia or its equivalent, 20 had surgery: six had a carcinoma, 12 had dysplasia without a carcinoma, and two had neither carcinoma nor dysplasia in the excised specimen. In five of the six patients found to have a carcinoma, a raised lesion associated with dysplasia was noted on endoscopy. Three of these lesions were at a distance from the carcinoma. Six of the 12 patients with high grade dysplasia but no carcinoma in the operation specimen also had a raised lesion detected at endoscopy. Four patients did not undergo surgery as all subsequent biopsy specimens were negative for dysplasia: three are alive and well $(17,19$, and 21 years later) and one died of an unrelated cause seven years later.

Eleven of 76 patients with lesser degrees of dysplasia later developed carcinoma. Three of them developed higher grades of dysplasia but in eight no higher grades of dysplasia were detected before surgery. Six other patients developed severe/high grade dysplasia without carcinoma. Most did not develop either severe dysplasia or carcinoma. The cumulative proportion who developed high grade dysplasia or carcinoma is shown in the figure, from which it will be seen that about $80 \%$ of patients with a biopsy specimen showing low grade dysplasia did not develop either high grade dysplasia or carcinoma within five years.

\section{Discussion}

Among 401 patients with colitis affecting most or all of the colon, but whose symptoms or disability did not warrant early surgical treatment, the cumulative probability of colorectal cancer was $5 \%$ after 20 years of disease and $9 \%$ after 25 years. The risk of developing either cancer or severe/high grade dysplasia was $13 \%$ at 25 years. If the 62 patients with extensive colitis diagnosed by colonoscopy and biopsy but not on $x$ ray, none of whom have developed high grade dysplasia or carcinoma, had been included the estimate would be lower. These are similar figures to the risk of carcinoma among patients with extensive colitis in a European study from three centres? ( $7 \cdot 2 \%$ at 20 years and $11 \cdot 6 \%$ at 25 years), patients in Stockholm County diagnosed between 1955 and 1979 (5\% at 20 years), ${ }^{8}$ and in an American private practice $(11 \cdot 7 \%$ at 26 years $) .{ }^{9}$ As in this series, patients in all these studies were treated surgically as necessary for acute or disabling colitis and the figures refer to those followed medically up to the time of surgery, death, or the end of follow up.

Earlier studies suggested a higher risk of carcinoma, ${ }^{10-12}$ perhaps because of selection bias $^{13}$ and because fewer patients were then referred for surgery. It is important to distinguish these results among patients with extensive colitis attending an outpatient clinic from those obtained in population studies from a defined geographical area which include patients with all extents of colitis including distal disease. Some of these studies yield similar figures for cancer incidence, as in Israel ( $5.5 \%$ at 20 years and $13.5 \%$ at 30 years), ${ }^{14}$ and others a lower incidence, as in Stockholm $(5.5 \% \text { at } 25 \text { years })^{8}$ or Copenhagen $(1.4 \%$ after 18 years $) .{ }^{15}$ It is not possible at present to estimate the cancer risk among patients with radiologically shown inflammation of the colon distal to the hepatic flexure. Nor is the risk known among patients with colitis found to be extensive at colonoscopy but with a barium enema which is normal or shows less extensive disease.

Our findings and other published reports thus suggest that the risk of colorectal cancer for a patient who has colitis, shown at some stage to affect most or all of the colon by barium enema, 
is about $12 \%$ during the period $10-25$ years after onset of symptoms. Patients who are troubled little by their colitis are usually unwilling to accept proctocolectomy to avoid a cancer risk of this degree even when a stoma can be avoided. For patients whose colitis is a cause of recurrent or chronic ill health, however, the cancer risk is an additional factor which may persuade them to undergo surgery.

Regular supervision can be offered to those patients who choose to avoid surgery yet who wish to minimise the risk of cancer. Clinical assessment includes enquiry about the patient's disability, recognition of a change of symptoms, digital examination of the anorectum, and sigmoidoscopy with biopsy and possibly brush cytology. Colonoscopy with biopsies and sometimes brushings is advisable at entry to the follow up and at regular intervals after the duration of disease reaches 10 years. Barium enema is needed if colonoscopy is incomplete or refused. Consultation at each clinic visit enables the patient to ask questions and express fears and the doctor to give advice on treatment, either medical or surgical, appropriate to the patient's disease, physical condition, and life situation.

Our results, and published series suggest that surveillance should begin early in the disease course and be continued with regular patient recall irrespective of symptoms. Such a programme is to be distinguished from those in which colonoscopy is undertaken for the first time in patients with longstanding colitis. Collins et $a l^{16}$ drew attention to the high proportion of advanced tumours in three reports. These series, ${ }^{17-19}$ however, include many patients with a long history of colitis referred for colonoscopy.

At the outset of this follow up it was hoped that precancerous changes (dysplasia) would be detected on biopsy specimen and colectomy would be performed at this stage, thus preventing the development of carcinoma. In the event, 12 patients with severe/high grade dysplasia accepted colectomy and the presence of this histological change was confirmed in the colectomy specimen. It is not certain that these patients would have developed carcinoma, but the likelihood seems high. It is noteworthy that operation was delayed for one to six years for five patients with high grade dysplasia in another series and all had a carcinoma at colectomy..$^{18}$ It does not seem ethical to follow patients with unequivocal severe/high grade dysplasia to establish its natural history because all series show that a quarter to a third of these, as in this series, have an undetected carcinoma elsewhere in the colon. The ethical dilemma has been well discussed in another context. ${ }^{20}$

Despite the finding of presumed precancerous changes in these 12 patients, carcinoma occurred in 22 others. Furthermore, the incidence of carcinoma was little different from that observed in series without regular follow up. Why was this so? Dysplasia as a marker of neoplastic potential, endoscopy, and clinical follow up all proved to have limitations.

Dysplasia is a descriptive finding which is subject to intra- and interobserver variation ${ }^{521} 22$ and an observer study on biopsy specimens obtained in this follow up has confirmed that overall agreement between pairs of experienced pathologists was only $42-65 \% .^{23}$ It is often a patchy change in the large intestine so that small biopsy specimens from random sites may not detect it. Carcinoma can occur in the absence of dysplasia at a distance from the tumour and, conversely, carcinoma may already be present when severe/high grade dysplasia is first detected. The most reliable marker of dysplasia is a proliferative lesion, either villous change or a polypoid area, in which epithelial changes of dysplasia are shown. ${ }^{19}$ Severe/high grade dysplastic changes in flat mucosa are less often associated with synchronous carcinoma and apparently false positive results can occur, as in six of 24 patients in this series. For this reason it is advisable that a report of high grade dysplasia in flat mucosa should be agreed independently by two pathologists familiar with these changes and confirmed in at least two sites in the colon or on two separate occasions before colectomy is advised.

The clinical importance of low grade dysplasia in flat mucosa is difficult to establish. In this series about one fifth of patients with a biopsy reported in this way later developed high grade dysplasia or a carcinoma over about five years, whereas in four fifths, further biopsy specimens showed no dysplastic change or no progression. A single report of low grade dysplasia in flat mucosa seems to be an indication for increased vigilance but not an indication for colectomy, though when found in association with a proliferative lesion colectomy is advisable. The repeated finding of low grade dysplasia in sequential biopsy specimens may also be an indication for colectomy. Dysplasia as the original authors suggested is an 'aid to cancer control': it is a useful but imperfect marker which may enable colectomy to be undertaken at a precancerous phase or carcinoma to be detected at a curable stage.

Endoscopy, though an essential part of a follow up programme in colitis, also has limitations. Since the colonic mucosa is often hyperaemic and inflammatory polyps may be present, it is more difficult to recognise dysplastic areas or carcinoma than in the normal colon where an abnormal area contrasts with the smooth pale background. Sigmoidoscopy proved to be a useful investigation because over half the biopsy specimens showing high grade dysplasia were obtained from the rectum or sigmoid colon, perhaps related to the fact that half the carcinomas occurred in these areas. However, colonoscopy is also essential to detect dysplasia or carcinoma limited to the proximal colon.

Follow up is limited by human factors, especially fear, forgetfulness, family or business commitments, advancing age, other illnesses, and moves from one place to another. As a result, $14 \%$ of patients left this follow up programme. To achieve follow up of the remaining $86 \%$ required considerable administrative effort, including letters of reminder, and intervals between visits exceeded one year at some stage in $63 \%$ of patients.

These difficulties of histological interpretation, endoscopic examination, and patient compliance are likely to affect any longterm follow up 
programme in colitis. Our results are probably representative of any similar programme conducted as part of overall clinical care, as distinct from a research programme devoted wholly to cancer surveillance. Did the programme reduce mortality among patients who developed carcinoma? Four representative surgical series $^{2+27}$ of carcinoma in ulcerative colitis show that about one third of tumours were disseminated at the time of presentation and only $41 \%$ were Dukes stage A or B. The five year survival rate of colorectal carcinoma complicating colitis in surgical series varied between 31 and $55 \% .{ }^{24252728}$

By contrast among the 344 patients who continued in the St Mark's programme with varying degrees of compliance, 12 were operated upon at a stage of precancer, and of the 17 who developed carcinoma, Dukes staging was A or B in $12(70 \%)$ and only two $(12 \%)$ developed disseminated fatal cancers. These results are encouraging and they are supported by results from four other surveillance programmes run on similar lines which included 577 patients. ${ }^{29-32}$ Among them, six were operated upon for high grade dysplasia without carcinoma, one Dukes stage A carcinoma was diagnosed at endoscopy, and four patients had unsuspected Dukes A or B tumours associated with high grade dysplasia.

In this series, five of 48 patients who ceased to attend developed carcinoma (three fatally) over 348 patient years. One other centre, ${ }^{31}$ in a review of all their patients with ulcerative colitis, reported on 84 lost to follow up: over 315 patient years, five developed carcinoma with three deaths. These figures were not obviously influenced by any selection bias and, although dealing with only small numbers, suggest a poorer outcome in unsupervised patients.

Evidence of the possible benefit of follow up programmes therefore comes from comparison with surgical series of unselected patients who developed carcinoma complicating colitis and from the mortality due to this complication among defaulting groups. Lead-time bias may reduce the apparent benefit of early diagnosis of carcinoma so that a corresponding reduction in mortality is not as great as expected. Selection bias may affect the prognosis of patients who default. Conclusive evidence of the efficacy of a follow up programme would come ideally from a comparison of longterm mortality in a randomly allocated surveillance group, a control group which is not followed, and preferably a group treated surgically. Such a comparison is likely to be impracticable. Informed consent would be needed, numbers would have to be large, and the duration of observation would need to be at least 10 years.

The results presented in this paper suggest that regular follow up in extensive colitis enables some patients to be treated at a stage of precancer and an equivalent number at an early (Dukes A) stage of carcinoma when cure is almost certain. Proof that such a programme reduces mortality will take many years. The resource implications of such programmes also need evaluation. The search for a better marker of premalignant change continues but at the moment dysplasia on biopsy specimen, possibly supplemented by brush cytology, ${ }^{33}$ is the best available. Patients with extensive colitis need regular follow up for general assessment and treatment. For the compliant patient with relatively few symptoms who wishes to avoid surgery, regular clinical and endoscopic supervision, with biopsies or brush cytology, or both, despite its limitations, remains a reasonable policy to lessen the cancer risk.

We gratefully acknowledge the help of Mr P Lennard-Jones and Mr S Edmeades of the ICRF Computer unit in the analysis of the results, and Miss Sharon Love of the ICRF statistical unit for he help and advice in the statistical analysis. Mr J M A Northover, Director of the ICRF Colorectal Cancer Unit has given constan encouragement. We would like to thank Miss Jane Brice, Sister Annie Driscoll and the staff of the outpatient department, Sister Margaret Boland and the staff of the endoscopy department, and the many others who have worked so hard to care for the patient with extensive ulcerative colitis at St Mark's Hospital. Man with exests pathologists have worked at the interpretation of the dysplastic
biopsy specimens, but we wish particularly to thank Dr J R Jass biopsy specimens, but
and Dr N A Shepherd.

1 Morson BC, Pang LSC. Rectal biopsy as an aid to cancer control in ulcerative colitis. Gut 1967;8:423-34.

2 Lennard-Jones JE, Misiewicz JJ, Parrish JA, Ritchie JK Swarbrick ET, Williams CB. Prospective study of outpatients with extensive colitis. Lancet 1974; i: 1065-7.

3 Lennard-Jones JE, Morson BC, Ritchie JK, Shove DC Williams CB. Cancer in colitis: assessment of the individua risk by clinical and histological criteria. Gastroenterology 1977; 73: 1280-9.

4 Lennard-Jones JE, Morson BC, Ritchie JK, Williams CB. Cancer surveillance in ulcerative colitis. Lancet 1983; ii: 14952.

5 Riddell RH, Goldman H, Ransohoff DF, et al. Dysplasia in inflammatory bowel disease: standardized classification with inflammatory bowel disease: standardized classification with
provisional clinical applications. Hum Pathol 1983; 14: 93168 .

6 Kaplan EL, Meier P. Nonparametric estimation from incomplete observations. F Am Stat Assoc 1958; 53: 457-81.

7 Gyde SN, Prior P, Allan RN, et al. Colorectal cancer in ulcerative colitis: a cohort study of primary referrals from three centres. Gut 1988; 29: 206-17.

8 Brostrom O, Lofberg R, Nordenvall B, Ost A, Hellers G. The risk of colorectal cancer in ulcerative colitis: an epidemiologic study. Scand F Gastroenterol 1987; 22: 1193-9.

9 Katzka I, Brody RS, Morris E, Katz S. Assessment of colorectal cancer risk in patients with ulcerative colitis: experience from a private practice. Gastroenterology 1983; 85: $22-9$.

10 DeDombal FT, Watts McK, Watkinson G, Goligher JC Local complications of ulcerative colitis: stricture pseudopolyposis and carcinoma of colon and rectum. Br Med $\mathcal{F}$ polyposis and carcin

11 Kewenter J, Ahlman H, Hulten L. Cancer risk in extensive colitis. Ann Surg 1978; 188: 824-8

12 Greenstein AJ, Sachar DB, Smith H, et al. Cancer in universal and left-sided ulcerative colitis: factors determining risk Gastroenterology 1979; 77: 290-4

13 Sackett DL, Whelan G. Cancer risk in ulcerative colitis scientific requirements for the study of prognosis. Gastroenterology 1980; 78: 1632-5.

14 Gilat T, Fireman Z, Grossman A, et al. Colorectal cancer in patients with ulcerative colitis: a population study in Central patients with ulcerative colitis: a popula
Israel. Gastroenterology 1988; 94: 870-7.

15 Hendriksen C, Kreiner S, Binder V. Long term prognosis in ulcerative colitis - based on results from a regional patient ulcerative colitis - based on results from a regional patient
group from the County of Copenhagen. Gut 1985; 26: 158group.

16 Collins RH, Feldman M, Fordtran JS. Colon cancer, dysplasia and surveillance in patients with ulcerative colitis: a critica review. N Engl F Med 1987; 316: 1654-8.

17 Nugent FW, Haggitt RC. Results of a long term surveillance program for dysplasia in ulcerative colitis. Gastroenterolog 1984; 86: 1197 .

18 Rosenstock E, Farmer RG, Petras R, Sivak MV, Rankin GB, Sullivan BH. Surveillance for colonic carcinoma in ulcerative colitis. Gastroenterology 1985; 89: 1342-6.

19 Blackstone MO, Riddell RH, Rogers BHG, Levin B. Dysplasia-associated lesion or mass (DALM) detected by Dysplasia-associated lesion or mass (DALM) detected by
colonoscopy in long-standing ulcerative colitis: an indication colonoscopy in long-standing ulcerative colitis: an inctor

20 Paul C. The New Zealand cervical cancer study: could it happen again? Br Med F 1988; 297: 533-9.

21 Dundas SAC, Kay R, Beck S, et al. Can histopathologists reliably assess dysplasia in chronic inflammatory bowe disease? F Clin Pathol 1987; 40: 1282-6.

22 Melville DM, Jass JR, Shepherd NA, et al. Dysplasia and Deoxyribonucleic acid-aneuploidy in the assessment of precancerous changes in chronic ulcerative colitis: observe variation and correlations. Gastroenterology 1988; 95: 66875

23 Melville DM, Jass JR, Morson BC, et al. Observer study on the grading of dysplasia in ulcerative colitis: comparison with clinical outcome. Hum Pathol 1990 (in press). 
24 Johnson WR, McDermott FT, Hughes ESR, Pihl EA, Milne $\mathrm{BJ}$, Price AB. Carcinoma of the colon and rectum in inflammatory disease of the intestine. Surg Gynecol Obstet 1983; 156: 193-7.

25 Van Heerden JA, Beart RW Jr. Carcinoma of the colon and rectum complicating chronic ulcerative colitis. Dis Colon rectum complicating chro

26 Mir-madjlessi SH, Farmer RG, Easley KA, Beck GJ. Colorectal and extracolonic malignancy in ulcerative colitis Cancer 1986; 58: 1569-74.

27 Ohman U. Colorectal carcinoma in patients with ulcerative colitis. Am F Surg 1982; 144: 344-9.

28 Gyde SN, Prior P, Thompson H, Waterhouse JAH, Allan RN. Survival of patients with colorectal carcinoma complicating ulcerative colitis. Gut 1984; 25: 228-31.
29 Brostrom O, Lofberg R, Ost A, Reichard H. Cancer surveillance of patients with longstanding ulcerative colitis: a clinical endoscopical, and histological study. Gut 1986; 27 : 1408-13.

30 Manning AP, Bulgim OR, Dixon MF, Axon ATR. Screening by colonoscopy for colonic epithelial dysplasia in inflammaby colonoscopy for colonic epithelial dysplasia in inflamma-

31 Jones HW, Grogono J, Hoare AM. Surveillance in ulcerative colitis: burdens and benefit. Gut 1988; 29: 325-31.

32 Rutegard J, Ahsgren L, Stenling R, Janunger KG. Ulcerative colitis: cancer surveillance in an unselected population. Scand $\mathcal{F}$ Gastroenterol 1988; 23: 139-45.

33 Melville DM, Richman PI, Shepherd NA, Williams CB, Lennard-Jones JE. Brush cytology of the colon and rectum in ulcerative colitis: an aid to cancer diagnosis. $\mathcal{F}$ Clin Pathol $1988 ; 41: 1180-6$ 